\title{
ANALISIS PENERAPAN PP 46 TAHUN 2013 ATAS PAJAK PENGHASILAN WAJIB PAJAK ORANG PRIBADI USAHAWAN DIBIDANG USAHA JASA PADA TOKO TONNY
}

\author{
Dayna M. Poluan ${ }^{1}$, Jullie J. Sondakh ${ }^{2}$, Heince R.N. Wokas ${ }^{3}$ \\ ${ }^{1,2,3}$ Fakultas Ekonomi dan Bisnis, Jurusan Akuntansi, Universitas Sam Ratulangi, Jl. Kampus Bahu. Manado, \\ 95115, Indonesia
}

Email : daynamagdalenapoluan96@gmail.com

\begin{abstract}
In 2013 the Government implemented the Income Tax Regulation, namely PP No. 46 of 2013 with a calculation scheme of $1 \%$ multiplied by turnover or gross profit and gross circulation of less than 4.8 billion per year. This study aims to determine the application of PP No. 46 of 2013 at Tonny Stores in accordance with the existing tax laws. This study uses descriptive analysis methods and data obtained through interviews and documentation. This study will also compare PP 46 of 2013 with the Calculation of Net Income Norms and the latest tax rules PP 23 of 2018. The results of this study indicate PP 46 of 2013 reduces the amount of tax paid compared to Net Income Calculation Norms and also makes it easy to calculate the amount Personal Income Tax is payable so that it can minimize errors in determining the amount of income tax that must be paid by the company.
\end{abstract}

Keywords: Income tax, Norma Calculations, PP 46 in 2013

\section{PENDAHULUAN}

Pajak merupakan salah satu sumber dana utama pendapatan negara dan merupakan sektor penting dalam pembangunan suatu negara. Sehingga pemerintah selalu mengadakan beragam usaha dalam memajukan pendapatan pada sektor pajak. Fungsi pemerintah serta wajib pajak amat penting dalam merealisasi pendapatan pajak di Indonesia. Ada beberapa macam pajak yang mempengaruhi pendapatan pajak negara salah satunya ialah PPh karena setiap warga negara Indonesia yang menghasilkan pendapatan dari dalam negeri maupun luar negeri akan dikenai $\mathrm{PPh}$. $\mathrm{PPh}$ yang merupakan beban bagi wajib pajak, membuat pemerintah harus mengambil tindakan dalam penyederhanaan dan pemerataan agar wajib pajak tidak terlalu terbeban dalam tarif pemotongannya.

Dari tahun ke tahun pemerintah terus mengupayakan agar wajib pajak terlebih bagi usahawan supaya dapat dengan mudah untuk membayar pajak dan meringankan besaran tarif pajak sehingga wajib pajak tidak merasa dirugikan dan pemerintah yang diuntungkan melainkan memiliki keadilan pada kedua belah pihak. Tahun 1983, reformasi pajak dilaksanakan dengan mengganti sistem pemungutan pajak dari official assessment system berubah jadi self-assessment system. Official assessment system merupakan sistem pemotongan pajak yang memberi kewenangan pemerintah untuk menentukan besarnya pajak yang terutang (Ikatan Akuntan Indonesia, 2013).

Sejak Juli 2013 pemerintah mengeluarkan peraturan pajak yang mengelola berlakunya PPh, yaitu Peraturan Pemerintah No. 46 Tahun 2013 tentang Pajak Penghasilan. Dalam peraturan tersebut telah ditentukan peredaran bruto yang dikenai Pajak Penghasilan yang bersifat final yaitu tidak lebih dari 4,8 miliar dan tarif pajaknya yaitu 1\%. Dengan berlakunya PP 46 tahun 2013 ini, maka wajib pajak diberikan kemudahan dalam penghitungan PPh terutangnya karena tidak menggunakan dasar pembukuan tetapi cukup mendasarkan pada catatan omset setiap bulan sehingga wajib pajak juga tidak diharuskan lagi untuk membayar 
angsuran pajak dan wajib pajak juga diberikan kemudahan dalam menghitung pajak karena hanya $1 \%$ dikalikan omset.

Tetapi pada Juli 2018 Pemerintah mengeluarkan peraturan pajak penghasilan yang baru yakni PP 23 Tahun 2018 dengan peredaran bruto kurang dari 4,8 miliar sama dengan peraturan sebelumnya yaitu PP 46 Tahun 2013 akan tetapi beda pada tarif potongan pajaknya yakni 0,5\% sedangkan PP 46 Tahun 2013 potongan tarif pajaknya 1\% dan dengan perhitungan yang sama yaitu menggunakan laba bruto atau omzet. Akan tetapi ada beberapa kebijakan pemerintah dalam peraturan pajak penghasilan yang baru ini. Penelitian ini bertujuan untuk mengetahui bagaimana pengaruh PP 46 Tahun 2013 wajib pajak orang pribadi usahawan dibidang usaha jasa pada Toko Tonny dibandingkan dengan menggunakan aturan lama yakni Norma Perhitungan dan jika menggunakan aturan terbaru yakni PP 23 Tahun 2018.

\section{TINJAUAN PUSTAKA}

Pengertian Akuntansi. Rudianto (2012:4) akuntansi adalah “Aktivitas mengumpulkan, menganalisis, menyajikan dalam bentuk angka, mengklasifikasikan, mencatat, meringkas, dan melaporkan aktivitas/transaksi suatu badan usaha dalam bentuk informasi keuangan." Akuntansi juga pada prinsipnya ialah sistem pengelolaan informasi yang menyajikan mengenai formasi akuntansi. Ada dua macam akuntansi yakni akuntansi keuangan dan akuntansi manajemen. Ada pun akuntansi dilihat dari sudut proses kegiatannya Suwardjono (2014:8) akuntansi diartikan dengan proses mencatat, menggolongkan, meringkas, melapor, dan menganalisis data keuangan suatu organisasi. Artian ini menunjukkan kegiatan akuntansi yaitu tugas yang kompleks dan menyangkut berbagai kegiatan.

Pengertian Pajak. Definisi pajak berdasarkan Undang-Undang Nomor 16 tahun 2009 tentang perubahan keempat atas Undang-Undang Nomor 6 tahun 1983 tentang Ketentuan Umum dan Tata Cara Perpajakan pada pasal 1 ayat 1 yang dikutip dari Mardiasmo (2016) menyatakan pajak merupakan kontribusi wajib kepada Negara yang terutang oleh orang pribadi atau badan yang bersifat memaksa berlandaskan Undang-Undang, dengan tidak mendapat pengembalian secara langsung dan dipakai dalam kebutuhan Negara bagi seluruh kemakmuran rakyat. Sedangkan menurut Mardiasmo (2016) pajak ialah iuran rakyat kepada kas Negara berlandaskan aturan dengan tiada menghasilkan kontraprestasi yang langsung bisa dinyatakan dan yang dipakai dalam membiayai kebutuhan umum.

Pengertian Akuntansi Perpajakan. Akuntansi pajak, ialah elemen dalam akuntansi yang muncul dari unsur khusus yang berdasar keterampilan pada sektor tertentu. Akuntansi pajak terbentuk karena adanya sebuah pendirian yang berlandaskan dan ditata dalam UU perpajakan dan pembuatannya dipengaruh oleh manfaat perpajakan dalam penerapannya sebagai prosedur dari pemerintah.

Pajak Penghasilan. Undang-undang $\mathrm{PPh}$ yang mengelola penggunaan Pajak Penghasilan atas subjek pajak berkaitan dengan pendapatan yang didapat atau dihasilkannya dalam tahun pajak.

Pajak Penghasilan Final. PPh Final merupakan pajak yaitu dipotong dengan tarif dan dasar penggunaan pajak terpilih atas pendapatan yang didapatkan selama tahun berjalan. Membayar, memotong, atau memungut PPh Final yang dikenakan pihak lain ataupun yang dibayar secara pribadi yaitu bukan dari pembayaran dimuka atas PPh terutang melainkan merupakan pendapatan pelunasan atas PPh terutang tersebut, sehingga wajib pajak dipercaya sudah melaksanakan pelunasan kewajiban perpajakan.

Peraturan Pemerintah No. 46 Tahun 2013. Pengenaaan PPh dilandaskan pada peredaran omzet dari kegiatan dalam 1 tahun yang tidak melebihi dari 4,8 miliar dan dengan 
potongan tarif pajak sebesar 1\%. PP 46 Tahun 2013 ini bersifat final sehingga hanya sekali dalam pemotongannya dan tidak bisa dikreditkan.

Norma Perhitungan Penghasilan Netto. Mardiasmo (2018) apabila dalam perhitungan Penghasilan Kena Pajak-nya Wajib Pajak memakai Norma Perhitungan Penghasilan Netto, banyaknya penghasilan netto ialah sama banyaknya dengan besaran Norma Perhitungan Penghasilan Netto dikalikan dengan total peredaran omzet dan pendapatan bruto pekerjaan lepas setahun.

Peraturan Pemerintah No. 23 Tahun 2018. Pada tanggal 1 Juli 2018 perubahan tarif yang efektif diberlakukan. Tarif PPh Final UMKM resmi turun dari $1 \%$ menjadi $0,5 \%$. Berubahnya tarif PPh Final UMKM itu terdapat dalam PP No. 23 Tahun 2018. Peraturan Pemerintah mengenai Pajak Penghasilan atas pendapatan dari kegiatan yang didapatkan atau diperoleh wajib pajak yang mempunyai peredaran bruto tertentu tersebut merupakan pengganti atas PP No. 46 Tahun 2013. Pemerintah telah menetapkan untuk meringankan tarif $\mathrm{PPh}$ final menjadi $0,5 \%$. Namun, penetapan ini bersifat pilihan karena wajib pajak bisa memilih untuk mengikuti tarif dengan skema final 0,5\%, atau tetap dengan memakai skema normal yang mengarah pada pasal 17 Undang-Undang No. 36 Tahun 2008 mengenai pajak penghasilan.

Penelitian Terdahulu. Ada beragam penelitian terdahulu yang penulis jadikan sebagai bahan evaluasi pada saat melaksanakan penelitian yakni yang dilakukan oleh Butarbutar (2014) dengan judul Penerapan PP No. 46 Tahun 2013 Pada UMKM (Studi Kasus Pada CV. Lestari Malang). Tujuan penelitian ini untuk mengetahui dampak penerapan PP No. 46 Tahun 2013 terhadap besarnya PPh Badan yang harus disetor oleh perusahaan. Hasil pada penelitian ini menunjukkan masih adanya kesalahan dalam perhitungan $\mathrm{PPh}$ Badan perusahaan sehingga pajak yang disetorkan lebih besar dari yang sebenarnya. Sedangkan untuk menyetor dan melaporkan PPh badan telah dilaksanakan sesuai aturan perpajakan. Diatmika (2013) dengan judul Penerapan Akuntansi Pajak Atas PP No. 46 Tahun 2013 Tentang PPh Atas Penghasilan Dari Usaha Wajib Pajak Yang Memiliki Peredaran Bruto Tertentu. Penelitian ini bertujuan untuk membandingkan kontribusi wajib pajak yang menerapkan PP 46 tahun 2013 dengan kontribusi wajib pajak yang tidak menerapkan PP 46 tahun 2013. Dari hasil penelitian menunjukkan PP No 46 tahun 2013 lebih berpihak pada pengusaha yang memiliki peredaran usaha dibawah 4,8 milyar per tahun untuk menetapkan tarif $1 \%$ bersifat final dari pada menetapkan tarif umum yang berlaku yakni $25 \%$. Dari perlakuan akuntansi sebaiknya pengusaha yang termasuk memiliki sifat khusus seperti UMKM menetapkan perlakuan akuntansi pajak yang bersifat final yakni sebesar $1 \%$ dari peredaran usaha setiap bulannya.

\section{METODE PENELITIAN}

Jenis Penelitian. Jenis penelitian yang digunakan dalam penelitian ini adalah penelitian deskriptif kualitatif. Kuncoro (2013:1) menyatakan bahwa penelitian deskriptif meliputi pengumpulan data untuk di uji hipotesis atau menjawab pertanyaan mengenai status terakhir dari subjek penelitian. Peneliti memilih pendekatan deskriptif dikarenakan dalam penelitian ini peneliti ingin mengetahui analisis dan penerapan Peraturan Pemerintah No.46 Tahun 2013 pada Toko Tonny.

Tempat dan Waktu Penelitian. Tempat penelitian yang dilaksanakan sebagai lokasi penelitian sesuai dengan judul penelitian dilakukan yaitu pada Toko Tonny. Waktu penelitian dimulai dari bulan Mei tahun 2018 sampai dengan selesainya peneliti.

Jenis Data Penelitian. Jenis data yang dipakai yaitu data kualitatif dan data kuantitatif. Data kualitatif yaitu hasil wawancara mengenai bagaimana penerapan Pajak Penghasilan PP 46 tahun 2013 pada Toko Tonny. Sedangkan data kuantitatif dalam penelitian ini merupakan hasil dokumentasi berupa gambaran umum perusahaan yaitu sejarah, visi misi, 
struktur kepemimpinan perusahaan, serta omset penjualan, laporan laba rugi perusahaan dan laporan Pajak Penghasilan Peraturan Pemerintah 46 tahun 2013 yaitu sebesar 1\% tahun 20162017 pada Toko Tonny.

Sumber Data Penelitian. Landasan data pada observasi ini yakni data primer. Sumber data bertujuan agar peneliti lebih mudah dalam mendapatkan dan mengumpulkan informasi yang diperlukan dalam penelitian untuk penarikan suatu kesimpulan. Data primer dalam penelitian ini adalah hasil wawancara dengan Pimpinan selaku pemilik perusahaan yang berkaitan dengan omset penjualan, laporan laba rugi perusahaan dan laporan Pajak Penghasilan yaitu PP 46 tahun 2013. Landasan data yang didapatkan yakni langsung dari wawancara.

Metode Pengumpulan Data. Metode pengumpulan data dalam penelitian ini dilakukan dengan cara sebagai berikut:

1. Wawancara. Suatu metode yang bertujuan untuk mendapatkan dan mengumpulkan data dengan mengadakan wawancara dalam hal ini tanya jawab dengan Pimpinan selaku pemilik perusahaan Toko Tonny yang dapat memberikan informasi mengenai penerapan PP 46 tahun 2013 pada perusahaan.

2. Dokumentasi. Penelitian yang dilakukan dengan cara menelaah atas dokumen-dokumen yang terkait dalam hal pemotongan pajak 1\% yaitu Peraturan Pemerintah No. 46 tahun 2013 pada Toko Tonny tahun 2017.

Metode dan Proses Analisis. Metode analisis data yang dipakai saat observasi ini yaitu analisis deskriptif kualitatif yaitu dengan cara menjelaskan kenyataan atas keadaan sebuah objek dalam bentuk uraian kata berlandaskan penjelasan dari beragam pihak yang berkaitan langsung dalam penelitian ini.

\section{HASIL PENELITIAN DAN PEMBAHASAN}

\subsection{Hasil Penelitian}

Penelitian ini dilakukan pada Toko Tonny, dari hasil penelitian yang dilakukan diperoleh hasil sebagai berikut ini :

\section{Laporan Laba Rugi Perusahaan}

Tabel 1. Laporan Laba Rugi Toko Tonny TOKO TONNY

LAPORAN LABA RUGI

TAHUN 2017

PENJUALAN

(-) HPP

LABA KOTOR

Rp. $361.500 .000,-$

Rp. 1.000.000.000,-

BEBAN USAHA :

BEBAN GAJI

BEBAN LISTRIK TELEPON

BEBAN OPERASIONAL KENDARAAN

BEBAN PERLENGKAPAN

TOTAL

LABA BERSIH

Rp. 578.520.000,-

(-) PAJAK

Rp. 6.385.000,-

LABA BERSIH SETELAH PAJAK

Rp.572.135.000,-

Sumber Data: TOKO TONNY

Rp. 45.600.000,-

Rp 7.540.000,-

Rp. 4.530.000,-

Rp. 2.310.000,-

Rp. 59.980.000,-

Rp. 638.500 .000 


\section{Perhitungan PP 46 Tahun 2013}

Tabel 2. Perhitungan PPh wajib pajak orang pribadi PP 46 tahun 2013 untuk data tahun 2017

\begin{tabular}{cllccc}
\hline No & Bulan & Penghasilan & Tarif & $\begin{array}{c}\text { Perhitungan (Tarif x } \\
\text { Peredaran Bruto) }\end{array}$ & $\begin{array}{c}\text { PPh WP } \\
\text { Pribadi } \\
\text { Terhutang }\end{array}$ \\
\hline 1 & Januari & Rp. 51.000.000,- & $1 \%$ & $1 \%$ x Rp. 51.000.000,- & Rp. 510.000,- \\
2 & Ferbruari & Rp. 50.500.000,- & $1 \%$ & $1 \%$ x Rp. 50.500.000,- & Rp. 505.000,- \\
3 & Maret & Rp. 52.600.000,- & $1 \%$ & $1 \%$ x Rp. 52.600.000,- & Rp. 526.000,- \\
4 & April & Rp. 53.000.000,- & $1 \%$ & $1 \%$ x Rp. 52.600.000,- & Rp. 530.000,- \\
5 & Mei & Rp. 53.000.000,- & $1 \%$ & $1 \%$ x Rp. 53.000.000,- & Rp. 530.000,- \\
6 & Juni & Rp. 53.000.000,- & $1 \%$ & $1 \%$ x Rp. 53.000.000,- & Rp. 530.000,- \\
7 & Juli & Rp. 54.000.000,- & $1 \%$ & $1 \%$ x Rp. 54.000.000,- & Rp. 540.000,- \\
8 & Agustus & Rp. 54.100.000,- & $1 \%$ & $1 \%$ x Rp. 54.100.000,- & Rp. 541.000,- \\
9 & September & Rp. 53.700.000,- & $1 \%$ & $1 \%$ x Rp. 53.700.000,- & Rp. 537.000,-- \\
10 & Oktober & Rp. 54.100.000,- & $1 \%$ & $1 \%$ x Rp. 54.100.000,- & Rp. 541.000,- \\
11 & November & Rp. 54.500.000,- & $1 \%$ & $1 \%$ x Rp. 54.500.000,- & Rp. 545.000,- \\
12 & Desember & Rp. 55.000.000,- & $1 \%$ & $1 \%$ x Rp. 55.000.000,- & Rp. 550.000,- \\
& Total & Rp.638.500.000,- & $1 \%$ & $1 \%$ x Rp.638.500.000,- & Rp. 6.385.000,- \\
\hline
\end{tabular}

Sumber Data: TOKO TONNY

Berdasarkan laporan Laba Rugi diatas Toko Tonny menghitung PPh Final UMKM Sebesar 1\% berdasarkan PP 46 Tahun 2013 dari Peredaran Bruto atau Penghasilan, dalam Laporan Laba Rugi diatas disebut Laba Kotor. Dari perhitungan dan pemotongan pajak PP 46 Tahun 2013 menurut perusahaan, dapat dilihat kalau Toko Tonny telah menghitung dan memotong pajak sesuai dengan Undang-Undang Perpajakan yang berlaku yaitu, Peraturan Pemerintah No. 46 Tahun 2013 yang tarif pajaknya sebesar 1\% dengan benar.

\subsection{Pembahasan}

Perhitungan Pajak dengan menggunakan Norma Perhitungan Penghasilan Netto (NPPN)

Tabel 3. Perhitungan PPh wajib pajak orang pribadi menurut NPPN tahun 2017

\begin{tabular}{lr}
\hline \multicolumn{1}{c}{ Keterangan } & Nominal \\
\hline Persentase Norma Perhitungan Pengasilan Netto Untuk Wajib Pajak & $30 \%$ \\
Orang Pribadi Jenis Usaha Toko Perdagangan Eceran Berbagai Macam & \\
Barang yang Utamanya Makanan, Minuman atau Tembakau Bukan di & \\
Supermarket/Minimarket (Tradisional) & \\
Penjualan (Penghasilan Toko) & \\
Hasil Penghasilan Netto Wajib Pajak Pribadi Bpk. Tonny & Rp. 1.000.000.000,- (x) \\
& Rp. 300.000.000,- \\
Penghasilan Tidak Kena Pajak (PTKP) Bpk. Tonny & \\
Orang Pribadi & \\
Kawin & (Rp. 54.000.000,-) \\
Anak Dua (2 x Rp.4.500.000,-) & (Rp. 4.500.000,-) \\
Penghasilan Kena Pajak (PKP) Bpl. Tonny & (Rp. 9.000.000,-) \\
Tarif dan Perhitungan Lapisan Pajak & Rp. 232.500.000,- \\
5\% x Rp. 50.000.000,-- & \\
10\% x Rp.182.500.000,- & \\
PPh Terutang dalam 1 Tahun & Rp. 2.500.000,- \\
\end{tabular}


Tabel 4. Perhitungan PPh wajib pajak orang pribadi terutang

\begin{tabular}{clrr}
\hline No Bulan & Penghasilan Netto & $\begin{array}{c}\text { PPh WP Pribadi } \\
\text { Terhutang }\end{array}$ \\
\hline 1 & Januari & Rp. 25.000.000,- & Rp. 2.450.000,- \\
2 & Ferbruari & Rp. 25.000.000,-- & Rp. 2.450.000,- \\
3 & Maret & Rp. 25.000.000,- & Rp. 2.450.000,- \\
4 & April & Rp. 25.000.000,- & Rp. 2.450.000,- \\
5 & Mei & Rp. 25.000.000,-- & Rp. 2.450.000,- \\
6 & Juni & Rp. 25.000.000,- & Rp. 2.450.000,- \\
7 & Juli & Rp. 25.000.000,- & Rp. 2.450.000,- \\
8 & Agustus & Rp. 25.000.000,-- & Rp. 2.450.000,- \\
9 & September & Rp. 25.000.000,- & Rp. 2.450.000,- \\
10 & Oktober & Rp. 25.000.000,- & Rp. 2.450.000,- \\
11 & November & Rp. 25.000.000,-- & Rp. 2.450.000,- \\
12 & Desember & Rp. 25.000.000,- & Rp. 2.925.000,- \\
& Total & Rp.300.000.000,- & Rp.29.875.000,- \\
\hline
\end{tabular}

Sumber Data: TOKO TONNY (Data Diolah)

Data diatas menunjukan $\mathrm{PPh}$ terutang yang harus dibayar oleh Toko Tonny tahun 2017 sebesar Rp 29.875.000 dengan pembayaran perbulan sebesar Rp 2.450.000. Perhitungan dengan menggunakan Norma Perhitungan Penghasilan Netto (NPPN), beban Pajak Penghasilan Pribadi yang harus dibayar oleh Toko Tonny sangat tinggi sehingga penerimaan pendapatan dari Toko Tonny akan berkurang karena harus menanggung beban pajak tersebut.

\section{Perhitungan dengan menggunakan PP 23 Tahun 2018}

Tabel 5. Perhitungan PPh Wajib Pajak Orang Pribadi PP 23 Tahun 2018 Data Tahun

\begin{tabular}{|c|c|c|c|c|c|}
\hline \multicolumn{6}{|c|}{2017} \\
\hline No & Bulan & Penghasilan & Tarif & $\begin{array}{c}\text { Perhitungan (Tarif } \mathrm{x} \\
\text { Peredaran Bruto) }\end{array}$ & $\begin{array}{c}\text { PPh WP } \\
\text { Pribadi } \\
\text { Terhutang }\end{array}$ \\
\hline 1 & Januari & Rp. 51.000.000,- & $0.5 \%$ & $0.5 \%$ x Rp. 51.000.000,- & Rp. 255.000,- \\
\hline 2 & Ferbruari & Rp. 50.500.000,- & $0.5 \%$ & $0.5 \%$ x Rp. $50.500 .000,-$ & Rp. 252.500,- \\
\hline 3 & Maret & Rp. 52.600.000,- & $0.5 \%$ & $0.5 \%$ x Rp. $52.600 .000,-$ & Rp. 263.000,- \\
\hline 4 & April & Rp. 53.000.000,- & $0.5 \%$ & $0.5 \%$ x Rp. 52.600.000,- & Rp. 265.000,- \\
\hline 5 & Mei & Rp. 53.000.000,- & $0.5 \%$ & $0.5 \%$ x Rp. $53.000 .000,-$ & Rp. 265.000,- \\
\hline 6 & Juni & Rp. 53.000.000,- & $0.5 \%$ & $0.5 \%$ x Rp. $53.000 .000,-$ & Rp. 265.000,- \\
\hline 7 & Juli & Rp. 54.000.000,- & $0.5 \%$ & $0.5 \%$ x Rp. $54.000 .000,-$ & Rp. 270.000,- \\
\hline 8 & Agustus & Rp. 54.100.000,- & $0.5 \%$ & $0.5 \%$ x Rp. $54.100 .000,-$ & Rp. 270.500,- \\
\hline 9 & September & Rp. 53.700.000,- & $0.5 \%$ & $0.5 \%$ x Rp. $53.700 .000,-$ & Rp. 268.500,- \\
\hline 10 & Oktober & Rp. 54.100.000,- & $0.5 \%$ & $0.5 \%$ x Rp. $54.100 .000,-$ & Rp. 270.500,- \\
\hline 11 & November & Rp. 54.500.000,- & $0.5 \%$ & $0.5 \%$ x Rp. $54.500 .000,-$ & Rp. 272.500,- \\
\hline 12 & Desember & Rp. 55.000.000,- & $0.5 \%$ & $0.5 \%$ x Rp. $55.000 .000,-$ & Rp. 275.000,- \\
\hline & & Rp.638.500.000,- & $0.5 \%$ & $\begin{array}{r}0.5 \% \times \\
\text { Rp.638.500.000 }\end{array}$ & Rp. 3.192.500,- \\
\hline
\end{tabular}

Sumber Data: TOKO TONNY (Data Diolah) 
Di karenakan pajak 0,5\% masih baru diterbitkan oleh Pemerintah dan belum diterapkan oleh perusahan maka dalam penelitian ini penulis mencoba untuk menghitung tarif pajak $0,5 \%$ dengan menggunakan laporan laba rugi dari tahun diatas. Berdasarkan data di atas yaitu data tahun 2017 menunjukkan perhitungan dengan menggunakan PP 23 Tahun 2018, beban Pajak Penghasilan Pribadi yang harus dibayar oleh Toko Tonny terbilang rendah sehingga memungkinkan penerimaan pendapatan dari Toko Tonny akan bertambah.

Perbandingan Hasil Pajak antara PP 46 Tahun 2013, NPPN, dan PP 23 Tahun 2018

Tabel 6. Perbandingan Perhitungan Pajak Toko Tonny Tahun 2017

\begin{tabular}{rlllr}
\hline No & \multicolumn{1}{c}{ Bulan } & $\begin{array}{c}\text { PP 46 Tahun } \\
\mathbf{2 0 1 3}(\mathbf{1 \%})\end{array}$ & NPPN & $\begin{array}{r}\text { PP 23 Tahun } \\
\mathbf{2 0 1 8}(\mathbf{0 , 5} \%)\end{array}$ \\
\hline 1 & Januari & Rp. 510.000,- & Rp. 2.450.000,- & Rp. 255.000,- \\
2 & Februari & Rp. 505.000,- & Rp. 2.450.000,- & Rp. 252.500,- \\
3 & Maret & Rp. 526.000,- & Rp. 2.450.000,- & Rp. 263.000,- \\
4 & April & Rp. 530.000,- & Rp. 2.450.000,- & Rp. 265.000,- \\
5 & Mei & Rp. 530.000,- & Rp. 2.450.000,- & Rp. 265.000,- \\
6 & Juni & Rp. 530.000,- & Rp. 2.450.000,- & Rp. 265.000,- \\
7 & Juli & Rp. 540.000,- & Rp. 2.450.000,- & Rp. 270.000,- \\
8 & Agustus & Rp. 541.000,- & Rp. 2.450.000,- & Rp. 270.500,- \\
9 & September & Rp. 537.000,- & Rp. 2.450.000,- & Rp. 268.500,- \\
10 & Oktober & Rp. 541.000,- & Rp. 2.450.000,- & Rp. 270.500,- \\
11 & November & Rp. 545.000,- & Rp. 2.450.000,- & Rp. 272.500,- \\
12 & Desember & Rp. 550.000,- & Rp. 2.925.000,- & Rp. 275.000,- \\
Total & & Rp. 6.385.000 & Rp.29.875.000,- & Rp. 3.192.500,- \\
\hline
\end{tabular}

Sumber Data: TOKO TONNY (Data Diolah

Berdasarkan data diatas ketika perusahaan sebelumya menerapkan Norma Pehitungan Penghasilan Neto dilihat dari jumlah beban pajak sebelumnya terbilang sangat tinggi dibandingkan ketika perusahaan menggunakan skema perhitungan Pajak Penghasilan PP 46 Tahun 2013 dengan tarif pajak 1\% dari penghasilan bruto. Hasil perbandingan dari jumlah beban pajak yang harus dibayar perusahaan sangat jauh berbeda. PP 46 Tahun 2013 juga memberikan penyederhanaan dalam perhitungan pajak penghasilan dibandingkan dengan Norma Perhitungan Penghasilan Netto karena perusahaan hanya menghitung omzet/laba bruto dan dikalikan dengan 1\%. Namun ketika dibandingkan dengan PP 23 Tahun 2018 yang tarif pajaknya sebesar $0,5 \%$ maka beban pajak yang dibayar oleh Toko Tonny lebih rendah lagi.

\section{KESIMPULAN DAN SARAN}

\subsection{Kesimpulan}

Berdasarkan penelitian yang dilakukan dengan menganalisa data, keterangan dan penjelasan yang ada maka penulis memperoleh suatu kesimpulan sebagai berikut:

1. Berdasarkan hasil penelitian penerapan PP 46 Tahun 2013 pada Toko Tonny perhitungannya sudah sesuai dengan Undang-Undang perpajakan yang berlaku.

2. Berdasarkan perhitungan menggunakan Norma Perhitungan Penghasilan Netto diketahui bahwa PPh yang harus dibayar oleh Toko Tonny cukup tinggi jika dibandingkan dengan perhitungan menggunakan PP 23 tahun 2018 yaitu $\mathrm{PPh}$ yang akan dibayar sangat rendah karena tarif pajaknya yang kecil yaitu $0,5 \%$. 
3. Dari antara PP 46 Tahun 2013, Norma Perhitungan Penghasilan Neto, dan PP 23 Tahun 2018 dilihat dari tarif pemotongan serta kesederhanaan perhitungan beban pajak $\mathrm{PPh}$ terutang maka yang paling efisien digunakan yaitu PP 23 Tahun 2018.

\subsection{Saran}

Dengan adanya peraturan pajak penghasilan terbaru yakni PP 23 Tahun 2018 dengan tarif pajak sebesar 0,5\% dan peredaran bruto yang sama dengan PP 46 tahun 2013 yaitu sebesar 4,8 miliar tidak menutup kemungkinan bagi Toko Tonny jika ingin menggunakan peraturan yang baru ini. Jika dilihat dari perhitungan yang dibuat oleh penulis tarif dengan $0,5 \%$ memberikan penurunan dari $\mathrm{PPh}$ terutang perusahaan sehingga memungkinkan menambah penghasilan dari perusahaan. Tetapi ada beberapa aturan dalam PP 23 Tahun 2018 ini salah satunya masa 7 tahun pajak bagi wajib pajak pribadi dan Toko Tonny masuk dalam kategori masa 7 tahun pajak. Jika diperkirakan selama 7 tahun kedepan ketika Toko Tonny membayar dengan tarif pajak $0,5 \%$ maka keuntungan dari penurunan $\mathrm{PPh}$ terutang sebesar 50\% selama 7 tahun kedepan. Tapi semua tergantung dari Toko Tonny apakah akan mengambil peluang dari PP 23 Tahun 2018 atau tidak.

\section{DAFTAR PUSTAKA}

Butar-Butar, E.Y.A. 2014. Penerapan PP No. 46 Tahun 2013 Pada UMKM (Studi Kasus Pada CV. Lestari). Skripsi. Universitas Brawijaya. Malang.

Diatmika, I Putu Gede. 2013. Penerapan Akuntansi Pajak Atas PP Nomor 46 Tahun 2013 Tentang PPh atas Pajak Penghasilan dari Usaha Wajib Pajak yang Memiliki Peredaran Bruto Tertentu. Jurnal Akuntansi Profesi. Vol.3, No.2.

Ikatan Akuntan Indonesia. 2013. Modul Pelatihan Pajak Terapan Brevet A \& B Terpadu. Ikatan Akuntan Indonesia. Jakarta.

Kuncoro, Mudrajat. 2013. Metode Riset Untuk Bisnis dan Ekonomi, Bagaimana Meneliti dan Menulis Tesis. Edisi Keempat. Penerbit Erlangga. Jakarta

Mardiasmo. 2016. Perpajakan Edisi Revisi. Andi Offset.Yogyakarta. 2018. Perpajakan Edisi Terbaru. Andi Offset.Yogyakarta.

Norma Perhitungan Penghasilan Netto Per-17/PJ/2015 tentang Lampiran 1 Peraturan Dirjen Pajak yaitu Daftar Persentase Norma Perhitungan Penghasilan Netto Untuk Wajib Pajak Orang Pribadi yang Menghitung Penghasilan Netonya. http:/www.pajak.go.id/sites/default/files/info-pajak/Lamp.201.pdf. Diakses 21 September 2018.

Peraturan Menteri Keuangan Republik Indonesia Nomor 107/PMK.011/2013 tentang Tata Cara Penghitungan, Penyetoran dan Pelaporan Pajak Penghasilan atas Penghasilan dari Usaha yang diterima Wajib Pajak yang Memiliki Peredaran Bruto tertentu. www.pajak.go.id/content/peraturan-menteri-keuangan-nomor-107pmk0112013. Diakses 5 April 2018.

Peraturan Pemerintah Nomor 23 Tahun 2018 tentang Pajak Penghasilan Atas Penghasilan dari Usaha yang Diterima atau Diperoleh Wajib Pajak yang memiliki Peredaran Bruto Tertentu. http://www.pajak.go.id/peraturan-pemerintah-nomor-23-tahun-2018. Diakses 19 September 2018.

Republik Indonesia, Undang-Undang Nomor 16 Tahun 2000 tentang Perubahan Kedua atas Undang-Undang Nomor 6 Tahun 1983 tentang Ketentuan Umum dan Tata Cara Perpajakan.

Rudianto. 2012. Pengantar Akuntansi: Konsep dan Teknik Penyusunan Laporan Keuangan. Erlangga. Jakarta.

Suwardjono. 2014. Teori Akuntansi Perekayasan Pelaporan Keuangan. Yogyakarta: BPFE. 